\title{
Venous Thromboembolism Prevention in Spontaneous Intracerebral Hemorrhage
}

\author{
Luca Masotti ${ }^{1, ~ *, ~ M a r i o ~ D i ~ N a p o l i ~}{ }^{2}$, Daniel Agustin Godoy ${ }^{3}$, Grazia Panigada $^{4}$, Stefano Spolveri ${ }^{5}$, \\ Gianni Lorenzini ${ }^{6}$, Giancarlo Landini ${ }^{5}$ \\ ${ }^{1}$ Internal Medicine, Santa Maria Nuova Hospital, Florence, Italy \\ ${ }^{2}$ Neurological Service, San Camillo de' Lellis Hospital, Rieti, Italy \\ ${ }^{3}$ Neurointensive Care Unit, Sanatorio Pasteur and Intensive Care Unit, Hospital San Juan Bautista, Catamarca, Argentina \\ ${ }^{4}$ Internal Medicine, SS Damiano and Cosma Hospital, Pescia, Italy \\ ${ }^{5}$ Internal Medicine, Borgo San Lorenzo Hospital, Florence, Italy \\ ${ }^{6}$ Emergency Medicine, Pontedera Hospital, Pisa, Italy
}

Email address:

luca.masotti@tin.it (L. Masotti)

\section{To cite this article:}

Luca Masotti, Mario Di Napoli, Daniel Agustin Godoy, Grazia Panigada, Stefano Spolveri, Gianni Lorenzini, Giancarlo Landini. Venous Thromboembolism Prevention in Spontaneous Intracerebral Hemorrhage. International Journal of Clinical and Experimental Medical Sciences. Vol. 1, No. 2, 2015, pp. 16-21. doi: 10.11648/j.ijcems.20150102.13

\begin{abstract}
Venous thromboembolism (VTE), encompassing for deep vein thrombosis (DVT) and pulmonary embolism (PE), represents the most feared complication in patients suffering from spontaneous intracerebral hemorrhage (ICH). The balance between VTE risk and the risk of hematoma expansion and/or re-bleeding is the cornerstone of prophylaxis which is based on non-pharmacological and pharmacological strategies. In the latest years results of three randomized clinical trials on non-pharmacological prophylaxis in ischemic and hemorrhagic stroke have been published. Intermittent pneumatic compression has shown to be effective in ICH compared to placebo, whereas graduated compression stockings failed to show their superiority over placebo. Few and low quality studies reported on pharmacological prophylaxis in ICH. Overall, these studies showed that pharmacological prophylaxis could be safe, but whether it is more effective than other non-pharmacological methods remains unclear. A meta-analysis of four randomized controlled studies showed that pharmacological prophylaxis significantly reduces the rate of pulmonary embolism. Consequently, recommendations from Scientific Societies for VTE prevention in ICH are based on weak literature evidence. In the present article, the Authors provide a review on VTE prevention in ICH and propose a practical algorithm for clinical management of this topic.
\end{abstract}

Keywords: Venous Thromboembolism, Prophylaxis, Intracerebral Hemorrhage

\section{Background}

Venous thromboembolism (VTE), encompassing deep vein thrombosis (DVT) and pulmonary embolism (PE), represents the most feared complications occurring in patients suffering from ICH (1).

Incidence of VTE in acute phase of ICH ranges from $2 \%$ $(0.7 \%$ PE, $1.3 \%$ DVT) in large studies to $15 \%$ for symptomatic VTE events to $75 \%$ for asymptomatic DVT events in smaller case series (2-4). Much recently, the randomized controlled CLOTS (Clots in Legs Or sTockings after Stroke) III trial showed a 30-day 17\% cumulative incidence of symptomatic and asymptomatic VTE in the arm of hemorrhagic stroke patients that were not receiving VTE prevention (5).
Timing of VTE events in patients suffering from cerebrovascular events such as ischemic and hemorrhagic stroke has been much recently described. In fact, in 5632 patients enrolled in the CLOTS I and CLOTS II trials, symptomatic and/or asymptomatic VTE events occurred in $11.4 \%$ of patients between the seventh and tenth day and $3.1 \%$ of patients between twenty-sixth and thirtieth day from stroke onset, respectively (6).

Risk factors for VTE in patients with ICH are represented by older age, female gender, obesity, prolonged bed-rest, legs paralysis, ICH lobar location, large hematoma volume, National Institute of Health Stroke Scale (NIHSS) score $\geq 12$, withdrawal of antithrombotic treatment in antithrombotic-related ICH, pro-hemostatic agents such as activated or non-activated prothrombin complex concentrates 
or recombinant activated factor VII used for prompt reversal in anticoagulants-related ICH (7-9).

Acute treatment of VTE events involves the use of anticoagulant therapy in full doses. Since the administration of full dose anticoagulant drugs is contraindicated in the acute phase of $\mathrm{ICH}$ due to the risk of hematoma expansion, pulmonary embolectomy and/or vena cava filters placement could be the alternative choices. However these procedures are invasive and not always free from serious complications. Therefore the risk of mortality in patients with $\mathrm{ICH}$ who develop a VTE event will increase considerably. In fact, VTE represents the second cause of mortality in patients with $\mathrm{ICH}$ after ICH its-self, encompassing for $5 \%$ of all-cause mortality (10-13).

Due to this background, VTE prevention represents a cornerstone in the practical management of acute and sub-acute phase of $\mathrm{ICH}$. The purpose of this article is to review on literature evidence on VTE prevention in $\mathrm{ICH}$.

\section{VTE Prevention in ICH}

The balance between VTE risk and the risk of hematoma enlargement and/or re-bleeding is of utmost importance for making decision on which is the optimal strategy for VTE prevention.

Hematoma enlargement occurs in around $38 \%$ of the cases in the first 24 hours from ICH onset $(14,15)$. Of this, $26 \%$ of patients develop a hematoma enlargement within 1 hour from symptoms onset, while the remaining $12 \%$ occurs in the remaining 20 hours. Re-bleeding is relatively uncommon. Much recently, in the INTERACT II trial re-bleeding occurred in $0.3 \%$ of patients (16). So, it is evident that, in the majority of ICH patients, the first $24-48$ hours are crucial in terms of mortality and neurological deterioration.

Strategies to prevent VTE in ICH patients are represented by non-pharmacological and pharmacological agents $(1,17)$.

Non-pharmacological agents are represented by mechanical strategies such as graduated compression stockings (GCS), intermittent pneumatic compression (IPC) and the plantar venous pump (PVP), which represents a subtype of IPC, vena cava filters placement and early mobilization (18).

The evidence of literature relating to mechanical prophylaxis in patients with $\mathrm{ICH}$ results from four randomized controlled trials.

The VICTORIAH study, which randomized 141 patients, compared the combination of IPC with GCS versus GCS alone. The combination of the two strategies was significantly superior in reducing the risk of VTE compared with GCS alone [4.7\% vs $15.9 \%$, RR 0.29 (95\% CI 0.08-1.0), RRA $11.2 \%$, RRR 71\%, NNT 9] (19).

Further evidence for the mechanical prophylaxis derived from the CLOTS trials that were aimed at evaluating the role of mechanical prophylaxis in the population of patients with acute stroke, despite population was mainly represented by patients with ischemic stroke $(5,20$, and 21). CLOTS I and II trials did not provide separate results for patients with ischemic and hemorrhagic stroke, so it is unclear whether the subgroup of patients with hemorrhagic stroke had different results from those with ischemic stroke. In summary, the CLOTS I trial showed that GCS did not provide significant prevention compared to placebo, significantly increasing the risk of skin lesions, while the CLOTS II trial showed that the GCS positioned to the root of the thighs were significantly superior to the GCS positioned below the knees for VTE prevention $(20,21)$.

In the CLOTS III trial IPC was tested against placebo for VTE prevention (5). Separate results for ischemic and hemorrhagic stroke were displayed. In this trial 163 patients with hemorrhagic stroke undergone to IPC were compared with 159 patients undergone to placebo. VTE prophylaxis with IPC was associated with a significant reduction in the risk of VTE [6.7 \% vs $17 \%$ (OR 0:36; 95\% CI: 0.17 to 0.75 ), RRA $10.3 \%$, RRR $64 \%$, NNT 10] (5). Of note, the CLOTS III showed that patients undergone to IPC presented a significant reduction in all-cause mortality in follow-up compared to patients undergone to placebo, despite this, results are not available for the subgroup of ICH patients alone (5).

Other possible strategies of non-pharmacological prophylaxis in ICH are represented by the vena cava filters placement and early mobilization. To now, the main indication for vena cava filters placement is represented by the absolute contraindication to anticoagulant therapy (22). Therefore, in this context the main role of vena cava filters should be reserved to patients with ICH who suffer from acute VTE events. Instead, concern exists for the prophylactic role of vena cava filters in ICH patients. There are no studies that have evaluated the role of prophylactic vena cava filters as a strategy for prevention of VTE in the acute phase of ICH. For this purpose, it is reasonable to reserve vena cava filters for patients with ICH who are at very high risk of VTE, such as patients with a history of recent (within 3 months) VTE episode or severe thrombophilia $(23,24)$. It is important to remark that once time the absolute contraindication ceases, vena cava filters should be removed. However, the removal rate is low, as it was shown by recent reports in the literature (25).

The role of early mobilization as a possible strategy for the prevention of VTE in ICH patients has not been previously investigated.

Randomized controlled clinical trials have clearly demonstrated the efficacy of pharmacological prophylaxis with unfractionated heparin (UFH) and low molecular weight heparins (LMWHs) or fondaparinux in reducing VTE in non-surgical patient with a good safety profile (26). However, these trials excluded patients with recent $\mathrm{ICH}$. Therefore, it is impossible to extrapolate recommendations for ICH patients from this literature evidence. Literature evidence shows that pharmacological VTE prevention in ICH patients is underused. Prabhakaran et al. showed that only $16.5 \%$ of 32.690 patients with spontaneous ICH received any VTE prophylaxis, 71.5\% and $27.5 \%$ of it being by UFH and enoxaparin, respectively (27).

Much recently, a systematic review of literature on studies was aimed to evaluate the efficacy in terms of prevention of VTE and safety in terms of hematoma expansion or 
re-bleeding of the pharmacological prophylaxis in ICH patients, found nine studies for around 1750 patients enrolled (1, 28-36). 981 patients received pharmacological prophylaxis, starting at 48 hours in $66.6 \%$ of cases and within a week in $97.6 \%$ of cases. Three studies were randomized and controlled, but one of these was the continuation of one of the previous two. Six studies were retrospective. In three studies, pharmacological prophylaxis was performed by using unfractionated heparin (UFH); in four studies low molecular weight heparins (LMWHs) were used; in two studies both UFH and LMWHs were tested. Two studies compared the pharmacological prophylaxis with mechanical prophylaxis by using GCS, two studies compared the efficacy and safety of UFH starting from different days (second, fourth and tenth day after the ICH event), one study evaluated the efficacy and safety of LMWHs in combination with IPC in patients with ICH with or without ventricular bleeding; in the other studies the pharmacological prophylaxis was compared to placebo. The presence of VTE was systematically detected in three studies, whereas in other three studies VTE was detected only in patients who showed clinical signs of VTE. In one study VTE was defined as fatal PE or death in the presence of clinical or electrocardiographic signs suggestive for $\mathrm{PE}$ detected after the analysis of medical data records. Overall, the overview of these nine studies showed that the pharmacological prophylaxis starting within 48-72 hours from ICH could be effective and safe, even in patients with the ventricular extension bleeding. However, the two studies in which the pharmacological prophylaxis was compared with mechanical agents showed no significant differences in VTE rate between methods (1).

Four of the above mentioned studies, containing a control group, were meta-analyzed (37). The meta-analysis showed that in patients with $\mathrm{ICH}$, pharmacological prophylaxis with UFH or LMWHs significantly reduces the risk of symptomatic and asymptomatic pulmonary embolism [RR 0.37 (95\% CI: 0.17 to 0.80 ), RRR $63 \%$ ], not significantly reduced the risk of symptomatic and asymptomatic DVT [RR 0.77 (95 \% CI: 0.44 to 1.34 ), RRR 23\%] and all-cause mortality [RR 0.76 (95\% CI: 0.57-1.03), RRR 24\%] without increasing the risk of hematoma expansion [RR $1.42(95 \% \mathrm{CI}$ : 0.57-3.53), RRI 42\%] (37) .

In the latest years some scientific organizations produced their recommendations (38-44) (Table 1). The strength of the recommendations is weak, especially for pharmacological prevention.

Table 1. Summary of recommendations on VTE prophylaxis in ICH.

\begin{tabular}{|c|c|c|c|c|}
\hline $\begin{array}{l}\text { Year of } \\
\text { relapse }\end{array}$ & Organization & Ref. & Recommended regimen for VTE prophylaxis & $\begin{array}{l}\text { Level of evidence } \\
\text { and grade of } \\
\text { recommendation }\end{array}$ \\
\hline 2011 & American College of Physicians (ACP) & 38 & $\begin{array}{l}\text { Pharmacologic prophylaxis with UFH or LMWHs or a related drug } \\
\text { is indicated unless the assessed risk for bleeding outweighs the } \\
\text { likely benefits. ACP recommends against the use of mechanical } \\
\text { GCS }\end{array}$ & IB \\
\hline 2012 & $\begin{array}{l}\text { American college of Chest Physicians } \\
\text { (ACCP) }\end{array}$ & 39 & $\begin{array}{l}\text { Pharmacological prophylaxis with LMWH or UFH started between } \\
\text { days } 2 \text { or } 4 \text { or mechanical prophylaxis with IPC are indicated. } \\
\text { Prophylaxis with LMWH should be preferred over UFH. } \\
\text { ACCP recommends against mechanical prophylaxis with GCS. }\end{array}$ & $\begin{array}{l}\text { IIC } \\
\text { IB } \\
\text { IB }\end{array}$ \\
\hline 2012 & Asian VTE guidelines & 40 & $\begin{array}{l}\text { Patients at high risk of bleeding such as those with ICH should not } \\
\text { be offered pharmacological prophylaxis. Alternative options such as } \\
\text { mechanical prophylaxis (IPC, GCS or both) or vena cava filters } \\
\text { should be considered if they are at high VTE risk. Pharmacological } \\
\text { method should be introduced only when the bleeding risk is } \\
\text { resolved. }\end{array}$ & GPP \\
\hline 2013 & $\begin{array}{l}\text { International Consensus Statement under } \\
\text { the auspices of the Cardiovascular Disease } \\
\text { Educational and Research Trust, European } \\
\text { Venous Forum, North American } \\
\text { Thrombosis Forum, International Union of } \\
\text { Angiology and Union Internationale du } \\
\text { Phlebologie. }\end{array}$ & 41 & IPC combined with GCS is recommended & moderate \\
\hline 2013 & $\begin{array}{l}\text { Sociedad Española de Neurología Study } \\
\text { Group for Cerebrovascular Diseases }\end{array}$ & 42 & $\begin{array}{l}\text { IPC combined with GCS is recommended in the first } 24 \text { hours } \\
\text { After } 24 \text { hours LMWH could be administered }\end{array}$ & $\begin{array}{l}\text { IB } \\
\text { IIbB }\end{array}$ \\
\hline 2014 & European Stroke Organization (ESO) & 43 & $\begin{array}{l}\text { GCS are not recommended, IPC is recommended } \\
\text { Insufficient evidence for making strong recommendation on how, } \\
\text { when and for pharmacological prophylaxis should be given }\end{array}$ & $\begin{array}{l}\text { Moderate/strong } \\
\text { Low/weak }\end{array}$ \\
\hline 2015 & $\begin{array}{l}\text { National Institute for Clinical Excellence } \\
\text { (NICE) }\end{array}$ & 44 & $\begin{array}{l}\text { Pharmacological prophylaxis is NOT recommended to prevent } \\
\text { DVT/PE in hemorrhagic stroke patients } \\
\text { Do not offer GCS for VTE prophylaxis; } \\
\text { Consider offering IPC }\end{array}$ & GPP \\
\hline 2015 & $\begin{array}{l}\text { American Heart Association/American } \\
\text { Stroke Association (AHA/ASA) }\end{array}$ & 45 & $\begin{array}{l}\text { IPC as soon as possible } \\
\text { GCS are not beneficial } \\
\text { UFH/LMWH after demonstration of bleeding cessation after 1-4 } \\
\text { days from ICH onset }\end{array}$ & $\begin{array}{l}\text { I A } \\
\text { IIIA } \\
\text { IIbB }\end{array}$ \\
\hline
\end{tabular}


Based on literature evidence and recommendations, we propose a possible flow chart for VTE prevention in ICH (Figure 1).

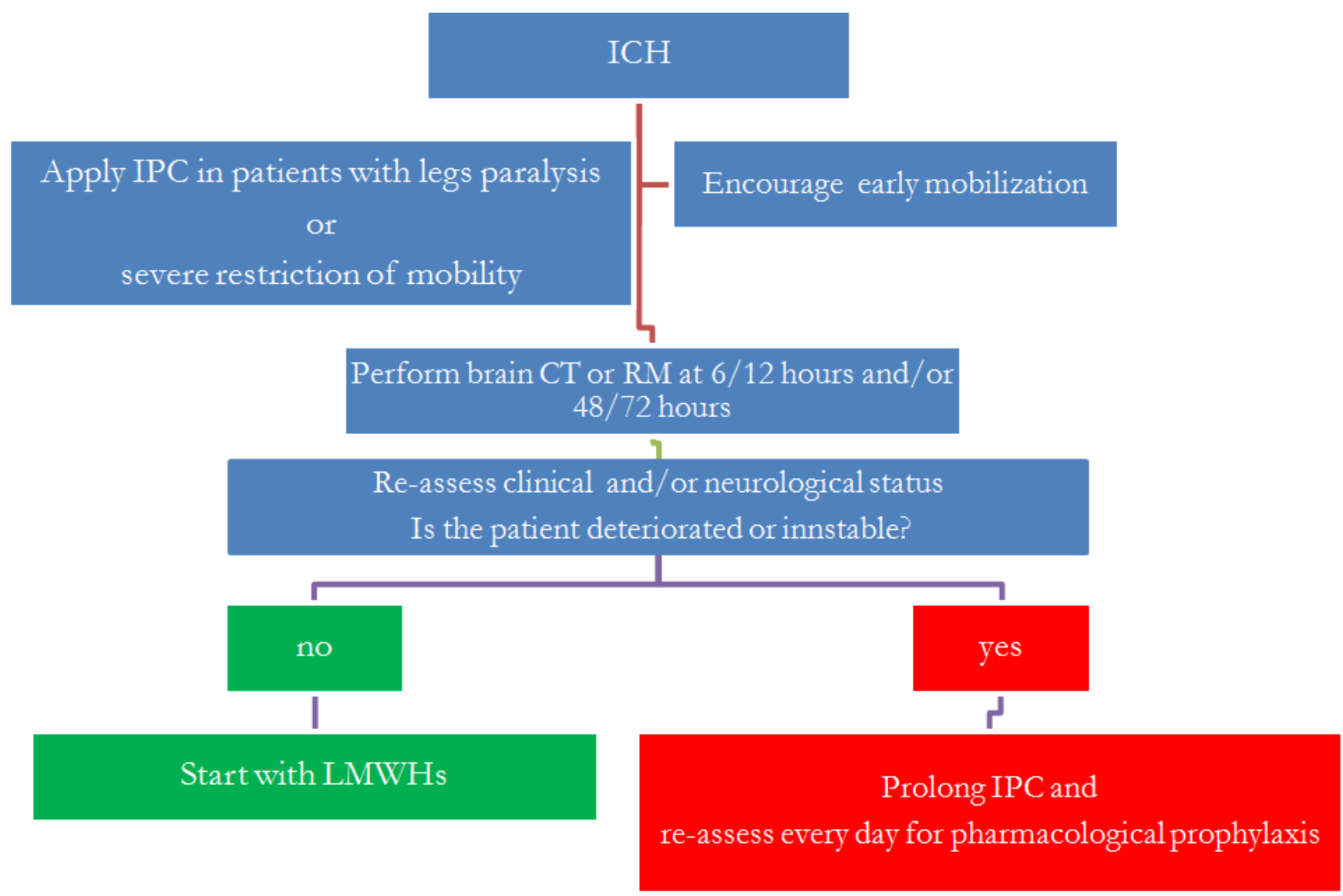

Figure 1. Proposed flow-chart for VTE prevention in ICH.

\section{Conclusion}

VTE is one of the most feared complications of spontaneous ICH, burdened by high mortality and morbidity. Therefore VTE prevention is of utmost importance. Literature lacks on suggesting the best practice for this purpose. IPC has shown to be effective and safe and therefore it should represent the first choice of treatment at least for the first 48-72 hours from symptoms onset. GCS is not recommended because it has shown to be ineffective. Evidence for pharmacological prophylaxis is weak. Prospective studies are warranted and necessary.

\section{References}

[1] Masotti L, Godoy D, Di Napoli M, Rabinstein A, Paciaroni M, Ageno W. Pharmacological prophylaxis of venous thromboembolism during acute phase of spontaneous intracerebral hemorrhage: what do we know about risks and benefits? Clin Appl Thromb Hemost 2012; 18; 393-402.

[2] Skaf E, Stein PD, Beemath A, Sanchez J, Bustamante MA, Olson RE. Venous thromboembolism in patients with ischemic and hemorrhagic stroke. Am J Cardiol 2005; 96: 1731-3.

[3] Wijdicks EF, Scott JP. Pulmonary embolism associated with acute stroke. Mayo Clin Proc 1997; 72: 297-300.
[4] Andrè C, de Freitas GR, Fukujima MM. Prevention of deep venous thrombosis and pulmonary embolism following stroke: a systematic review of published articles. Eur J Neurol 2007; 14: $21-32$.

[5] CLOTS (Clots in Legs Or sTockings after Stroke) Trials Collaboration. Effectiveness of intermittent pneumatic compression in reduction of risk of deep vein thrombosis in patients who have had a stroke (CLOTS 3): a multicenter randomized controlled trial. Lancet 2013; 382: 516-24.

[6] Dennis M, Mordi N, Graham C, Sandercock P; CLOTS trials collaboration. The timing, extent, progression and regression of deep vein thrombosis in immobile stroke patients: observational data from the CLOTS multicenter randomized trials. J Thromb Haemost 2011; 9: 2193-200.

[7] Kim KS, Brophy GM. Symptomatc venous thromboembolism: incidence and risk factors in patients with spontaneous or traumatic intracranial hemorrhage. Neurocrit Care 2009; 11: 28-33.

[8] Masotti L, Landini GC, Panigada G. The practical management of bleedings during treatment with direct oral anticoagulants: the emergency reversal therapy. Ital J Med 2013; 7 (suppl 8): $48-58$.

[9] Masotti L, Di Napoli M, Godoy D et al. The practical management of intracerebral hemorrhage associated with oral anticoagulant therapy. Intern J Stroke 2011; 6: 228-40 
[10] Qureshi AI, Mendelow AD, Hanley DF. Intracerebral haemorrhage. Lancet 2009; 373: 1632-44.

[11] Kappelle LJ. Preventing deep vein thrombosis after stroke: strategies and recommendations. Curr Treat Opt Neurol 2011; 13: $629-635$

[12] He C, Von Segesser LK, Kappetein PA, Mestres CA, Smith JA, Choong CK. Acute pulmonary embolectomy. Eur J Cardiothorac Surg 2013; 43: 1087-95

[13] Baglin TP, Brush J, Streiff $M$ for British Committee for Standards in Hematology. Guidelines on use of vena cava filters. Br J Hematol 2006; 134: 590-595.

[14] Wartenberg K, Mayer Sa. Reducing the risk of $\mathrm{ICH}$ enlargement. J Neurol Sci 2007; 261: 99-107.

[15] Rodriguez-Luna D, Rubiera M, Ribo M et al. Ultra early hematoma growth predicts poor outcome after acute intracerebral hemorrhage. Neurology 2011; 77: 1599-604.

[16] Anderson CS, Heeley E, Huang $\mathrm{Y}$ et al. INTERACT 2 Investigators. Rapid blood-pressure lowering in patients with acute intracerebral hemorrhage. N Engl J Med 2013; 368: 2355-65

[17] Caprini JA. Mechanical methods for thrombosis prophylaxis. Clin Appl Thromb Hemost 2010; 16: 668-673.

[18] Masotti L, Di Napoli M, Lorenzini G et al. Non pharmacological prophylaxis of venous thromboembolism in acutely ill medical patients. Cardiology and Angiology: an International Journal 2014; 2: 1-14

[19] Lacut K, Bressollette L, Le Gal G et al.; VICTORIAh (Venous Intermittent Compression and Thrombosis Occurrence Related to Intra-cerebral Acute hemorrhage) Investigators. Prevention of venous thrombosis in patients with acute intracerebral hemorrhage. Neurology. 2005; 65: 865-9.

[20] CLOTS Trials Collaboration, Dennis M, Sandercock PA, Reid J, Graham C, Murray G, Venables G, Rudd A, Bowler G. Effectiveness of thigh-length graduated compression stockings to reduce the risk of deep vein thrombosis after stroke (CLOTS trial 1): a multicenter, randomized controlled trial. Lancet. 2009; 373: $1958-65$.

[21] The CLOTS (Clots in Legs or Stockings after Stroke) Trial Collaboration. Thigh-Length Versus Below-Knee Stockings for Deep Venous Thrombosis Prophylaxis After Stroke. A Randomized Trial. Ann Intern Med 2010; 153: 553-62.

[22] Imberti D, Ageno W, Dentali F, Donadini M, Manfredini R, Gallerani M. Retrievable vena cava filters: a clinical review. J Thromb Thrombolysis 2012; 33: 258-66.

[23] Baron TH, Kamath PS, McBane RD. Management of antithrombotic therapy in patients undergoing invasive procedures. N Eng J Med 2013; 368: 2113-2124.

[24] Liew NC, Chang YH, Choi G et al. Asian venous thromboembolism guidelines: prevention of venous thromboembolism. Int Angiol 2012; 31: 501-516

[25] Swami U, Annunziata G, Fulger I. Experience With Vena Cava Filters at a Large Community Hospital and Level-I Trauma Center: Indications, Complications, and Compliance Barriers. Clin Appl Thromb Hemost 2013. In press

[26] Dentali F, Douketis JD, Gianni M, Lim W, Crowther MA. Meta-analysis: anticoagulant prophylaxis to prevent symptomatic venous thromboembolism in hospitalized medical patients. Ann Intern Med 2007; 146: 278-88.

[27] Prabhakaran S, Herbers P, Khoury J, Adeoye O, Khatri P, Ferioli S, Kleindorfer DO. Is prophylactic anticoagulation for deep venous thrombosis common practice after intracerebral hemorrhage? Stroke 2015; 46: 369-75.

[28] Dickmann U, Voth E, Schicha H, Henze T, Prange H, Emrich D. Heparin therapy, deep-vein thrombosis and pulmonary embolism after intracerebral hemorrhage. Klin Wochenschr 1988; 66: 1182-3.

[29] Boeer A, Voth E, Henze T, Prange HW. Early heparin therapy in patients with spontaneous intracerebral haemorrhage. J Neurol Neurosurg Psychiatry 1991; 54: 466-7.

[30] Kleindienst A, Harvey HB, Mater E, Bronst J, Flack J, Herenz K, Haupt WF, Scon R. Early antithrombotic prophylaxis with low molecular weight heparin in neurosurgery. Acta Neurochir (Wien), 2003; 145: 1085-91.

[31] Harvey RL, Lovell LL, Belanger N, Roth EJ. The Effectiveness of Anticoagulant and Antiplatelet Agents in Preventing Venous Thromboembolism During Stroke Rehabilitation: A Historical Cohort Study. Arch Phys Med Rehabil 2004; 85:1070-5.

[32] Tetri S, Hakala J, Juvela S, Saloheimo P, Pyhtinen J, Rusanen H, Savolainen ER, Hillbom M.. Safety of lowdose subcutaneous enoxaparin for the prevention of venous thromboembolism after primary intracerebral haemorrhage. Thromb Res 2008; 123: 206-12.

[33] Wasay M, Khan S, Zaki KS, Khealani BA, Kamal A, Azam I, Khatri IA. A non-randomized study of safety and efficacy of heparin for DVT prophylaxis in intracerebral hemorrhage. J Pak Med Assoc 2008; 58: 362-4.

[34] Orken DN, Kenangil G, Ozkurt H, Guner C, Gundogdu L, Basak M, Forta H. Prevention of deep venous thrombosis and pulmonary embolism in patients with acute intracerebral hemorrhage. Neurologist 2009; 15: 329-31.

[35] Kiphuth IC, Staykov D, Köhrmann M et. Early Administration of Low Molecular Weight Heparin after Spontaneous Intracerebral Hemorrhage. Cerebrovasc Dis 2009; 27: 146-50.

[36] Wu TC, Kasam M, Harun N et al. Pharmacological deep vein thrombosis prohylaxis does not lead to hematoma expansion in intracerebral hemorrhage with intraventricular extension. Stroke 2011; 42: 705-709.

[37] Paciaroni M, Agnelli G, Venti M, Alberti A, Acciarresi M, Caso V. Efficacy and Safety of Anticoagulants in the prevention of venous thromboembolism in patients with acute cerebral hemorrhage. A Meta-Analysis of Controlled Studies. J Thromb Haemost 2011; 9: 893-8.

[38] Qaseem A, Chou R, Humphrey LL, Starkey M, Shekelle P for the Clinical Guidelines Committee of the American College of Physicians. Venous thromboembolism prophylaxis in hospitalized patients: a clinical practice guideline from the American College of Physicians. Ann Intern Med 2011; 155: 625-32.

[39] Lansberg MG, O'Donnell MJ, Khatri P et al. Antithrombotic and Thrombolytic Therapy for Ischemic Stroke: Antithrombotic Therapy and Prevention of Thrombosis, 9th ed: American College of Chest Physicians Evidence-Based Clinical Practice Guidelines. Chest 2012; 141 (2 Suppl): e601S-36S. 
[40] Liew NC, Chang YH, Choi G, et al. Asian venous thromboembolism guidelines: prevention of venous thromboembolism. Int Angiol 2012; 31: 501-516.

[41] Nicolaides A, Fareed J, Kakkar AK et al. Prevention and Treatment of Venous Thromboembolism International Consensus Statement (Guidelines according to scientific evidence) Medical Patients. Clin Appl Thromb Haemost 2013; 19: 163-171.

[42] Rodríguez-Yáñez M, Castellanos M, Freijo MM et al. Clinical practice guidelines in intracerebral haemorrhage. Neurologia
2013; 28: 236-49.

[43] Steiner T, Al-Shahi Salman R, Beer R et al. European Stroke Organisation (ESO) guidelines for the management of spontaneous intracerebral hemorrhage. Int J Stroke 2014; 9: 840-55.

[44] Hemphill JC 3rd, Greenberg SM, Anderson CS et al. Guidelines for the Management of Spontaneous Intracerebral Hemorrhage: A Guideline for Healthcare Professionals From the American Heart Association/American Stroke Association. Stroke. 2015; Epub ahead of print. 